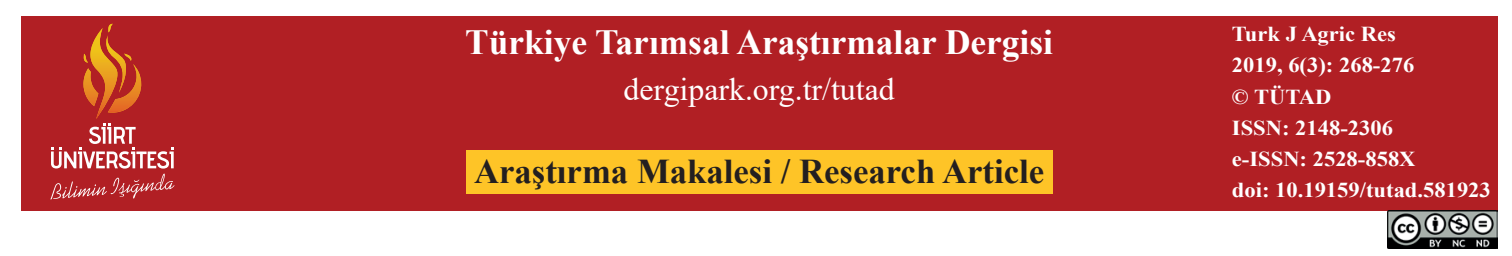

\title{
Karasal İ́klim Kuşağında Yer Alan İki Farklı Yükseltideki Doğal Meraların Vejetasyon Yapısı*
}

\author{
Ferhat KARAMAN, Nizamettin TURAN** \\ Siirt Üniversitesi, Ziraat Fakültesi, Tarla Bitkileri Bölümü, Sïrt, TÜRKIYE
}

\begin{tabular}{ll}
\hline \multicolumn{1}{c}{ Geliş Tarihi/Received: 25.06 .2019} & Kabul Tarihi/Accepted: 12.11 .2019 \\
\hline ORCID ID (Yazar sırasina göre / by author order) & \\
\hline (Dorcid.org/0000-0001-7929-2541 (Dorcid.org/0000-0002-4026-6781 & \\
${ }^{*}$ Sorumlu Yazar/Corresponding Author: nturan49@gmail.com &
\end{tabular}

Öz: Bu çalıșma; Türkiye'nin Güneydoğu Anadolu Bölgesi'nde yer alan doğal bir meranın farklı yükseltilerinin vejetasyon yapısını belirlemek amacıyla 2018 yılında yürütülmüsşür. Modifiye Edilmiş Tekerlekli Lup (halka) metodu kullanılarak yapılan bu çalışma ile iki farklı yükseltideki (sırasıyla $863 \mathrm{~m}$ ve $1083 \mathrm{~m}$ ) meranın bitki örtüsü ve vejetasyon yapısı incelenmiştir. Çalışma alanında bitkiyle kaplı alan, botanik kompozisyon, tür sayıları, mera durumu ve sağlı̆̆ gibi özellikler tespit edilmiştir. Araştırma sonucuna göre; birinci yükseltide $(863 \mathrm{~m})$ ortalama bitki ile kaplı alan \% 63, ikinci yükseltide $(1083 \mathrm{~m})$ ise \% 59 olarak belirlenmiştir. Birinci yükseltide bitki ile kaplı alanda buğdaygillerin, baklagillerin ve diğer familyaların oranı sırasıyla $\% 19.5, \% 17.25$ ve $\% 26.25$ olarak belirlenirken, ikinci yükseltide bu oran sırasıly $\% 15.0$, $\% 14.75$ ve \% 29.25 olarak gerçekleşmiștir. Bitki ile kaplı alanda botanik kompozisyondaki buğdaygillerin ortalama oranı $\% 28.06$, baklagillerin oranı $\% 26.08$ ve diğer familyalara ait bitkilerin oranı ise $\% 45.86$ olarak saptanmıştır. Meranın botanik kompozisyonu üzerinde yapılan incelemelere göre mera durumu "zayıf mera", mera sağlığı ise "riskli mera" sınıfında değerlendirilmiştir. Bu nedenle çalışmaya konu olan mera alanları ile bölgede bulunan diğer benzer alanlarda mera amenajman ilkelerine uyulması ve ıslah çalışmalarının yapılması gerektiği sonucuna varılmıştır.

Anahtar Kelimeler: Mera, bitki ile kaplı alan oranı, buğdaygiller, baklagiller, botanik kompozisyon

\section{Vegetation Structure of Natural Rangelands at Two Different Altitudes in Terrestrial Climate Zone}

\begin{abstract}
This study was conducted in 2018 to determine the vegetation structure of different altitudes of a natural rangeland in Turkey's Southeastern Anatolia Region. The plant cover and vegetation structure of the rangeland in two different elevations (863 and $1083 \mathrm{~m}$, respectively) were investigated by using modified wheel loop method. In the study area, features such as plant covered area, botanical composition, number of species, rangeland status and health were determined. According to the results of the research; the average plant-covered area was $63 \%$ at the first altitude $(863 \mathrm{~m})$ and $59 \%$ at the second altitude $(1083 \mathrm{~m})$. In the first altitude, the ratio of grasses, legumes, and other families in the area covered with plants was determined as $19.5 \%, 17.25 \%$ and $26.25 \%$, respectively; while in the second altitude, this rate was $15.0 \%, 14.75 \%$ and $29.25 \%$, respectively. In the area covered with plants, the average rate of grasses in botanical composition was $28.06 \%$, the rate of legumes was $26.08 \%$ and the rate of other families was $45.86 \%$. According to the evaluations on the botanical composition of the rangeland, the status was evaluated as "poor rangeland" and health was evaluated as "risky rangeland". For this reason, it is concluded that the rangeland areas and other similar areas in the region should be complied with the principles of rangeland management and breeding studies.
\end{abstract}

Keywords: Rangeland, plant cover percentage, Poaceae, Fabaceae, botanical composition

\footnotetext{
*: Bu çalışma; Siirt Üniversitesi, Fen Bilimleri Enstitüsü tarafından kabul edilen birinci yazara ait "Siirt İli Kurtalan İlçesi Çayırlı Köyü’nün Farklı Yükseltilere Sahip Merasının Vejetasyon Özelliklerinin Belirlenmesi” isimli Yüksek Lisans Tez çalışmasından üretilmiştir.
} 


\section{Giriş}

Hayvanların ihtiyaç duyduğu kaba yemlerin sağlandığı kaynakların en başında gelen çayırmeraların, ucuz ve kaliteli kaba yem sağlamasının yanı sıra hayvanın sağlığı, döl verimi, ahırda eksik aldığı vitamin ve mineral maddelerin tamamlanması gibi birçok yararları bulunmaktadır. Meralar aynı zamanda, doğal ve genetik kaynakların korunması ve sürdürülebilirliği gibi çok önemli ekonomik ve ekolojik faydası olan doğal bitki alanlarıdır. $\mathrm{Bu}$ alanlarda, farklı ekolojilerde yayılma yeteneğine sahip buğdaygil ve baklagil yem bitkileri familyaları ve diğer familyalara ait bitkiler de yer almaktadır. Böylece, meralardaki bitki tür ve çeşitliliğinin fazlalığı nedeniyle otlayan hayvanlar daha dengeli beslenebilmektedir.

Ancak meraların büyük bir çoğunluğunun kurak ve yarı kurak iklim kuşağında yer alması ve yağışın düşüklüğü ile birlikte otlatma planlarının olmaması veya uyulmaması gibi etmenler meralarda bitki örtüsünün bozulmasının en önemli sebeplerinden (Holechek ve ark., 2004) olup; Türkiye'de ise yıllardan beri süregelen ve tekniğine uygun olmayan kullanımlar sonucunda büyük çoğunluğu bozulan meraların, verim potansiyelleri ve ot kaliteleri çok düşmüş durumdadır (Gökkuş, 1991). Böylece, uygun olmayan kullanımın olumsuz etkilerinin yanı sıra uzun süre devam eden anormal iklim ve çevre koşulları ile diğer sosyoekonomik faktörlerin etkisiyle meralarda verimlilik önemli ölçüde zarar görebilmekte, yanlış kullanım diğer faktörlerin olumsuz etkilerini artırmaktadır (Altın ve ark., 2011). Bununla birlikte, aşırı ve zamansız otlatma meralarda bitkisel üretimi olumsuz yönde etkilemesinin sonucu olarak mera bitki tür kompozisyonunda arzulanan kaliteli bitki türlerinin oranlarında azalma, düşük yem kalitesine sahip bitki türlerinde ise artışa sebep olduğu (Altın ve ark., 2011), aşırı otlatma sonucunda meralarda bulunan hayvansal üretimi artırıcı bitki toplulukları yerine istilacı türler hakim olmaya başladı̆̆ (Açıkgöz, 1995; Bakoğlu ve Koç, 2002) araştırıcılar tarafından ifade edilmektedir.

Ayrıca, Türkiye'de önceki yıllarda yapılan mera etüdü çalışmalarında, botanik kompozisyondaki klimaks bitki türlerinin büyük çoğunluğunun say1 ve oran bakımından oldukça azaldığı, bazılarının ise tamamen kaybolduğu rapor edilmiştir (Aydın ve Uzun, 2000; Töngel ve Ayan, 2005; Ayan ve ark., 2007; Uzun ve ark., 2010; Ünal ve ark., 2011; Yavuz ve ark., 2012; Turan ve ark., 2015). Diğer yandan, Yıldız ve Özyazıcı (2017) tarafından da ifade edildiği üzere, Doğu Anadolu Bölgesi'nde mera ıslahına temel teşkil edecek çalışmaların az sayıda olması sebebiyle, mera vejetasyonlarının durumunun tespit edilmesine yönelik çalışmaların yapılması önem taşımaktadır.

Bu araştırma; Türkiye'nin Güneydoğu Anadolu Bölgesi'nde yer alan Siirt ili Kurtalan ilçesine bağlı Çayırlı Köyü'nün iki farklı yükseltideki doğal mera vejetasyonunun bazı özelliklerini belirlemek amacıyla yürütülmüştür.

\section{Materyal ve Yöntem}

Araştırma; Türkiye'nin Güneydoğu Anadolu Bölgesi'nde yer alan Siirt ili Kurtalan ilçesine bağlı Çayırlı Köyü merasının 863 m ve 1083 m rakımlı iki farklı mera kesiminde (Şekil 1) 2017 yılında yürütülmüştür. Araştırma alanı, Siirt il merkezine $44 \mathrm{~km}$, Kurtalan ilçe merkezine ise $14 \mathrm{~km}$ uzaklıkta olup, $37^{\circ} 55^{\prime} 33^{\prime \prime}$ kuzey enlemi ve $41^{\circ} 36^{\prime} 19^{\prime \prime}$ doğu boylamı arasında yer almaktadır.

Tipik karasal iklimin hâkim olduğu Siirt ili Kurtalan ilçesinin uzun yıllar ortalama yağış miktar1 $572.9 \mathrm{~mm}$, nispi nem \% 52.8, sicaklık ise $17.5{ }^{\circ} \mathrm{C}$ olarak ölçülmüştür. Araştırmanın yapıldığ 1 yılda ortalama nispi nem \% 54.0, yağ ${ }_{1 S ̧}$ $519.7 \mathrm{~mm}$, sicaklık ise $17.3{ }^{\circ} \mathrm{C}$ olarak gerçekleşmiştir. İklim verilerine göre; araştırma bölgesinin uzun yıllara göre nispeten daha serin, daha az yağışlı ve daha nemli olduğu söylenebilir (Tablo 1).

İncelenen mera alanının iki farklı yükseltisinden alınan toprak örneklerinin bazı fiziksel ve kimyasal analiz sonuçları Tablo 2'de sunulmuştur. Toprak analiz sonuçları incelendiğinde; her iki mera yükseltisinin ortalama değerlerine göre mera topraklarının; killi tekstürlü, tuzsuz, hafif alkalin karakterli, organik madde miktarının iyi, kireç içeriğinin az, alınabilir fosfor ve potasyum kapsamlarının ise orta düzeyde olduğu tespit edilmiştir (Tablo 2).

Vejetasyon çalışmasının yapıldığı merada, aralarındaki kot fark1 220 m olan 2 farklı kesimde (863 m ve $1083 \mathrm{~m}$ ) yürütülmüştür. Meranın botanik kompozisyonunu belirlemek için yapılan vejetasyon ölçümleri, Modifiye Edilmiş Tekerlekli Lup (halka) metodu kullanılarak Koç ve Çakal (2004)'in ifade ettiği şekilde hâkim bitkilerin çiçeklenme evresinde, her durakta 4 hatta ve toplam 400 noktada; doğu, bat1, kuzey ve güney yönleri esas alınarak, bitki okunmak suretiyle yapılmıştır. Lup ölçümleri; her bir merada vejetasyon ve toprak açısından oldukça homojen olan ve her blokta merkez olarak kabul edilen bir noktadan itibaren noktalar arası mesafe $50 \mathrm{~cm}, 4$ ana yöneye (doğu, bat1, kuzey ve güney) doğru uzanan 20 m'lik 4 hat üzerinde toplam 100 ve her blokta 400 olmak üzere bitki okuması yapılmıştır (Gökkuş ve ark., 2000). 


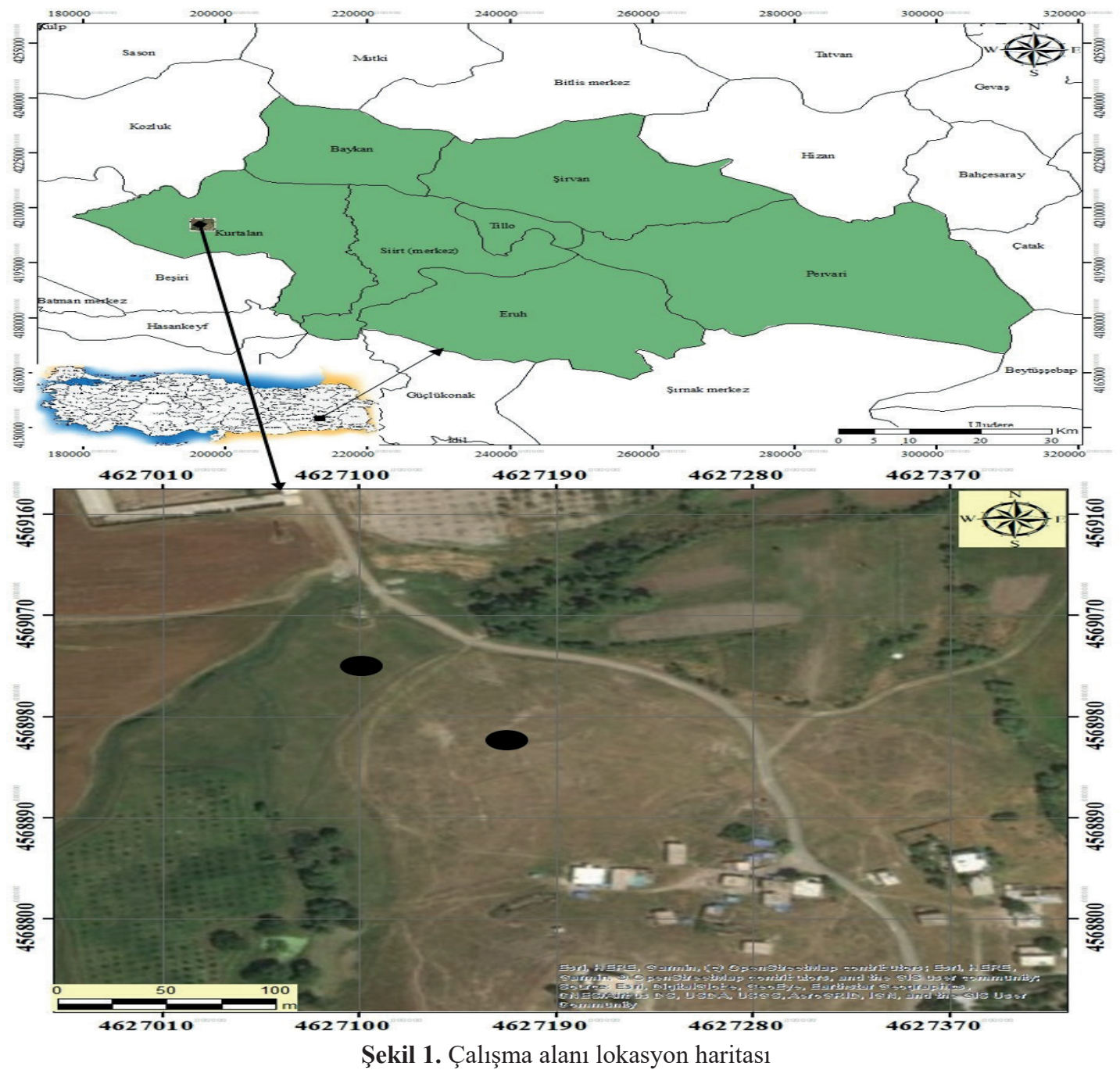

Tablo 1. Siirt ili Kurtalan ilçesinin bazı iklim verileri (Anonim, 2017)

\begin{tabular}{|c|c|c|c|c|c|c|}
\hline \multirow{2}{*}{ Aylar } & \multicolumn{2}{|c|}{ Ortalama sicakl1k $\left({ }^{\circ} \mathrm{C}\right)$} & \multicolumn{2}{|c|}{ Toplam yağıș (mm) } & \multicolumn{2}{|c|}{ Nispi nem (\%) } \\
\hline & Uzun yıllar & 2017 y1l1 & Uzun yıllar & 2017 y1l1 & Uzun yıllar & 2017 y1l1 \\
\hline Ocak & 3.1 & 2.8 & 82.7 & 51.6 & 81.9 & 76.4 \\
\hline Şubat & 6.1 & 2.3 & 57.6 & 21.6 & 71.2 & 74.6 \\
\hline Mart & 10.3 & 10.0 & 124.7 & 144.3 & 70.9 & 71.8 \\
\hline Nisan & 14.9 & 14.0 & 69.5 & 141.8 & 66.9 & 83.8 \\
\hline Mayıs & 20.1 & 19.3 & 50.0 & 78.2 & 59.1 & 84.9 \\
\hline Haziran & 27.4 & 27.3 & 7.0 & 1.2 & 28.8 & 27.8 \\
\hline Temmuz & 32.7 & 33.0 & 3.1 & 0.0 & 18.6 & 16.2 \\
\hline Ağustos & 32.6 & 32.4 & 1.3 & 2.5 & 17.8 & 17.1 \\
\hline Eylül & 27.1 & 28.4 & 11.1 & 0.0 & 24.0 & 17.5 \\
\hline Ekim & 19.2 & 18.6 & 45.6 & 11.0 & 46.0 & 34.0 \\
\hline Kasım & 10.3 & 11.3 & 45.1 & 41.5 & 67.3 & 69.0 \\
\hline Aralık & 5.6 & 8.3 & 75.2 & 26.0 & 80.5 & 75.1 \\
\hline Toplam/Ortalama & 17.5 & 17.3 & 572.9 & 519.7 & 52.8 & 54.01 \\
\hline
\end{tabular}

Vejetasyon çalışmasında tespit edilen bitki türleri azalıcılar, çoğalıcılar ve istilacılar olmak üzere 3 grup altında incelenmiştir (Anonim, 2008). İncelenen bitkilerden azalıcıların tamamı, çoğalıcıların oranları ise \% 20'si dikkate alınarak "Mera Durumu" sınıflaması yapılmıştır (Alay ve ark. 2016; Uzun ve ark. 2016). Mera durumu ve sağlığı sınıflamasının yapılmasında kullanılan değerler Tablo 3'te yer almaktadır (Koç ve ark., 2003).

Vejetasyon çalışmasında belirlenen her bir bitki türüne ait değerler toplam bitki sayısına oranlanarak 
Tablo 2. Araştırma alanı topraklarının bazı fiziksel ve kimyasal özellikleri $(0-20 \mathrm{~cm})^{*}$

\begin{tabular}{lccc}
\hline \multirow{2}{*}{ Toprak özelliği } & \multicolumn{2}{c}{ Değeri } \\
\cline { 2 - 3 } & 863 m yükseltisi & 1083 m yükseltisi & Ortalama \\
\hline Suyla doygunluk, $\%$ & 85.0 & 83.0 & 84.0 \\
pH & 8.13 & 8.15 & 8.14 \\
Organik madde, $\%$ & 4.46 & 4.25 & 4.36 \\
Kireç $(\mathrm{CaCO} 3), \%$ & 2.15 & 3.70 & 2.92 \\
Toplam tuz, \% & 0.13 & 0.15 & 0.14 \\
Alınabilir fosfor, $\mathrm{kg} \mathrm{P}_{2} \mathrm{O}_{5} \mathrm{da}^{-1}$ & 4.72 & 1.98 & 3.35 \\
Alınabilir potasyum, $\mathrm{kg} \mathrm{K}_{2} \mathrm{O} \mathrm{da}^{-1}$ & 7.11 & 6.51 & 6.81 \\
\hline
\end{tabular}

*: Analizler, Diyarbakır GAP Uluslararası Tarımsal Araştırma ve Eğitim Merkezi Müdürlüğü, Toprak Analiz Laboratuvarı’nda yapılmıştır.

Tablo 3. Mera durum ve sağlık sınıfı değerlendirmesi

\begin{tabular}{cccc}
\hline Mera durum sınıflamas1 & & \multicolumn{2}{c}{ Mera să̆lı̆̆ sınıflamas1 } \\
\hline Hesaba katılan türlerin oranı (\%) & Durum sınıfi & Toprağı kaplama oranı (\%) & Sağlık sınıf1 \\
\hline $76-100$ & Çok iyi & $>70$ & Sağlıklı \\
$51-75$ & İyi & $55-70$ & Riskli \\
$26-50$ & Orta & 55 & Sorunlu \\
$0-25$ & Zayıf & & \\
\hline
\end{tabular}

*: Modifiye edilmiş tekerlekli halka yöntemi verilerine göre uyarlanmıştır.

türlerin botanik kompozisyondaki oranları, taşl1lık ile boş alan oranı ise taşlık nokta sayısının, ölçülen toplam nokta sayısına oranlanması ile belirlenmiştir. Bununla birlikte, mera kesimlerinde bitkiye rastlanan nokta sayısının ölçülen toplam nokta sayısına oranlanması ile bitki örtüsünün toprağı kaplama oranı tespit edilmiştir (Gökkuş ve ark., 2000).

Vejetasyon etütleri esnasinda rastlanılan bitkilerin teşhisleri için; Edgecombe (1964), Garms ve ark. (1968), Davis (1969), Polunin ve Huxley (1974), Huxley ve Taylor (1977), Weymer (1981), Demiri (1983), Öztan ve Okatan (1985)'nın eserlerinden yararlanılmıştır. Türlerin ömür uzunlukları, familyaları ve etkilerinin belirlenmesi ise Anonim (2008)'e göre yapılmıştır.

\section{Bulgular ve Tartışma}

\subsection{Bitki ile kaplı alan}

Türkiye'de yapılan mer'a vejetasyonu çalışmalarında bitki örtüsündeki türler genelde buğdaygiller, baklagiller ve diğer familyalar olarak sınıflandırıldığını ifade eden Koç (1995)'un yöntemine göre; araştırma alanındaki bitki türleri buğdaygiller, baklagiller ve diğer familyalara ait bitki grupları olmak üzere toplam üç kategoride incelenmiştir.

Tablo 4'te görüldüğü gibi, incelenen merada bitki ile kaplı alan (BKA) birinci yükseklikte $\% 63.0$ olarak belirlenirken, ikinci yükseklikte \% 59.0 olarak tespit edilmiştir. Birinci yükseklikte bitki ile kaplı alanda \% 19.5 buğdaygiller, \% 17.25

Tablo 4. Siirt ili Kurtalan ilçesi Çayırlı Köyü merasına ait bitki ile kaplı alan (BKA) değerleri*

\begin{tabular}{llrr}
\hline & Familyalar & BKA (\%) & Toplam BKA (\%) \\
\cline { 2 - 4 } Yükseklik & Buğdaygiller & 19.50 & 63.00 \\
$(863 \mathrm{~m})$ & Baklagiller & 17.25 & 37.00 \\
& Diğer familya bitkileri & 26.25 & 100.00 \\
\cline { 2 - 4 } & Boş alan & 37.00 & 59.00 \\
\cline { 2 - 4 } & Toplam & 100.00 & 41.00 \\
\hline \multirow{4}{*}{ Yükseklik } & Buğdaygiller & 15.00 & 100.00 \\
& Baklagiller & 14.75 & \\
& Diğer familya bitkileri & 29.25 & 61.00 \\
\cline { 2 - 4 } & Boş alan & 41.00 & 39.00 \\
\cline { 2 - 4 } & Toplam & 100.00 & 100.00 \\
\hline
\end{tabular}

*: Modifiye edilmiș tekerlekli halka yöntemine göre belirlenmiștir. 
baklagiller ve \% 26.25 diğer familyalardan, ikinci yükseklikte ise \% 15.0 buğdaygiller, \% 14.75 baklagiller ve \% 29.25 diğer familyalardan bitkiler oluşturmaktadır (Tablo 4).

Bitki ile kaplı alan değerleri incelendiğinde; Dursun ve Babalık (2018) Isparta merasında \% 42.6, Çınar ve ark. (2018) Adana meralarında \% 95.3, Palta ve Genç Lermi (2018) Bartın meralarında \% 100, Babalik ve Ercan (2018) Eskişehir meralarında \% 51.2, Seydoşoğlu ve ark. (2018) Mardin meralarında \% 71.35, Seydoşoğlu ve Kökten (2019) Batman meralarında \% 81.06, Seydoşoğlu ve ark. (2019) Batman ili Kozluk ilçesi meralarında \% 84.7 olarak tespit ettiklerini rapor etmişlerdir. Bitki ile kaplı alan oranları ile yukarıdaki araştırıcıların bulgularıyla benzerliklerin ve farklılıkların olduğu tespit edilmiştir. $\mathrm{Bu}$ farklılıkların nedeni, ekolojik koşullar, toprak özellikleri ve kullanılan vejetasyon ölçme yöntemlerinden kaynaklandığ 1 söylenebilir.

Ayrica; mera kesimlerinde buğdaygiller, baklagiller ve diğer familyalara ait bitki türleri üç grup altında incelenmiş ve bitki ile kaplı alana göre botanik kompozisyondaki oranları belirlenmiştir. Bitkilerin botanik kompozisyondaki değerleri incelendiğinde; buğdaygillerin ve baklagillerin birinci yükseklikteki oranı (sırasıyla \% 30.70 ve $\%$ 27.17), ikinci yükseklikteki orana (sırasıyla \% 25.42 ve \% 25.00) göre daha fazla iken; diğer familyaların birinci yükseklikteki oranı (\% 42.13), ikinci yükseklikteki orana (\% 49.58) göre daha az olduğu saptanmıştır. Botanik kompozisyonda ortalama buğdaygillerin oranı \% 28.06, baklagillerin oranı \% 26.08 ve diğer familyaların oranı ise \% 45.86 olarak gerçekleşmiştir (Tablo 5). İncelenen mera kesimlerinin botanik kompozisyonu ortalamaya göre değerlendirildiğinde; vejetasyonda yer alan diğer familyalardan bitkilerin oranı daha yüksek olup, dominant bitki grubunu oluşturmaktadır. Bu durum mera kesimlerinin hatalı mera yönetimi uygulamaları ile ağır otlatma baskısına maruz kaldığı, dolayısıyla diğer familya bitkileri ile kaplı alan oranının yüksek olmasına neden olduğu düşünülmektedir.

Tablo 5. BKA miktarına göre botanik kompozisyon değerleri (\%)

\begin{tabular}{|c|c|c|c|}
\hline \multirow{2}{*}{ Familyalar } & \multicolumn{2}{|c|}{ Yükseltiler } & \multirow{2}{*}{ Ortalama } \\
\hline & $863 \mathrm{~m}$ & $1083 \mathrm{~m}$ & \\
\hline Buğdaygiller & 30.70 & 25.42 & 28.06 \\
\hline Baklagiller & 27.17 & 25.00 & 26.08 \\
\hline Diğer familya bitkileri & 42.13 & 49.58 & 45.86 \\
\hline Toplam & 100.00 & 100.00 & 100.00 \\
\hline
\end{tabular}

Bazı araştırıcılar bitki ile kaplı alan miktarına göre botanik kompozisyonu; Seydoşoğlu (2018) Diyarbakır meralarında buğdaygiller \% 22.82, baklagiller \% 40.66 ile diğer familya bitkileri ise $\%$ 36.52, Palta ve Genç Lermi (2018) Bartın meralarında buğdaygiller \% 28.5, baklagiller $\% 18.2$ ve diğer familya bitkileri \% 53.3, Babalık ve Ercan (2018) Eskişehir meralarında buğdaygiller $\% 44.0$, baklagiller \% 23.0 ve diğer familya bitkileri $\%$ 33.0, Dursun ve Babalik (2018) Isparta meralarında buğdaygiller \% 52.44, baklagiller $\% 18.04$ ve diğer familya bitkileri \% 29.52 olarak tespit ettiklerini rapor etmişlerdir.

Çalışmada elde edilen bulgular ile yukarıda belirtilen bazı literatür bulguları arasında benzerlikler ve farklılıklar bulunmaktadır. Bu farklılıklara iklim özellikleri, topoğrafik faktörler, erken ve kapasitesinin üzerindeki aşırı otlatmaların neden olduğu söylenebilir.

\subsection{Bitki familyaları ile ilgili bazı özellikler}

Araştırma alanındaki bitki türleri; çayır ve mera bitki örtülerinin durumlarını inceleyen araştırıcıların (Gökkuş, 1994; Tuna, 2000; Çomaklı ve ark., 2012) da ifade ettikleri gibi ömür uzunlukları tek (annual), iki yıllık (biannual) ve çok (perennial) yıllık ve yem değeri, üreme ve çoğalma yeteneklerine göre istilacı, çoğalıcı ve azalıcı şeklinde sınıflandırılarak; buğdaygiller, baklagiller ve diğer familyalar olmak üzere üç grup altında incelenmiștir. İncelenen bitki türlerinin birinci ve ikinci yükseklikteki özellikleri Tablo 6'da sunulmuştur. Buna göre; birinci yükseklikte 6 adet buğdaygil, 4 adet baklagil ve 10 adet diğer familya bitkileri olmak üzere toplam 20 adet familya tespit edilirken, ikinci yükseklikte 5 adet buğdaygil, 5 adet baklagil ve 7 adet diğer familyalardan bitki grupları olmak üzere toplam 17 adet familya belirlenmiştir. Mera kesiminin birinci yükseltisinde bulunan bitkilerin \% 95'i (19 adet) tek yıllık ve $\%$ 5'i (1 adet) çok y1llı, ikinci yükseltide ise bitkilerin \% 76.48'i (13 adet) tek y1llik ve \% 23.52'si (4 adet) çok yıllık olduğu saptanırken, birinci yükseklikteki bitkilerin \% 100'ünün (20 adet) istilacı, ikinci yükseklikteki bitkilerin $\%$ 88.24'ünün (15 adet) istilacı ve \% 11.76'sının ise (2 adet) çoğalıcı olduğu tespit edilmiştir (Tablo 6).

Mera vejetasyonlarında yapılan bazı çalışmalarda tespit edilen bitkilerin ömür uzunlukları ile ilgili; Babalık ve Ercan (2018) Eskişehir meralarında 57 adet çok yıllık, 2 tanesi iki y1llık ve 30 tanesinin ise tek yıllık, Palta ve Genç Lermi (2018) Bartın meralarında 12 tanesinin tek yıllık, 42 tanesinin çok yıllık, Seydoşoğlu (2018) Diyarbakır meralarında 26 tanesinin tek yıllık, 9 tanesinin çok yıllık, 1 tanesinin iki yıllık olduğu araştırıcılar tarafından ifade edilmektedir.

Çalışma konusu mera kesimlerinin botanik kompozisyonunda yer alan bitki türlerini ömür 
uzunluklarına göre değerlendirildiğinde; tek yıllık istilacı türlerin çoğunlukta olduğu görülmektedir. $\mathrm{Bu}$ durum meraların amenajman ilkelerine uyulmadan kapasitesinin üzerinde otlatıldı ğı ve ileri derecede tahrip olduğu sanılmaktadır. Bazı araştırıcılar (Adams ve ark., 1986; Laycock, 1989; Fitter, 1994), çok ileri derecede tahrip olmuş bitki örtülerinde tek yıllık türlerde hem sayı, hem de yoğunluk yönünden artış olduğu ifade etmektedir. Otlatma esnasında hayvanlar daha çok taban veya tabana yakın mera kesimlerini tercih etmeleri aşırı otlatılmaya neden olmaktadır. Böylece kapasitesinin üzerinde otlatılan meraların botanik kompozisyonundaki doğal dengenin tek yıllık türlerin lehine dönüşebileceği ve bu da ikinci yükseklikteki çok y1llık türlerin oranı, birinci yükseklikteki orana göre daha fazla olmasına neden olduğu düşünülmektedir.
Elde edilen bulgulardan mera alanının kötü kullanımı sonucu aşırı derecede yıprandığı ve tahrip edildiği, bu nedenle de iyi cins yem bitkileri türlerinin vejetasyondan kaybolduğu anlaşılmaktadır. Bilakis Holechek ve ark. (2004), çoğalıcı ve istilacı bitkilerin oranlarının fazla olması meraların kötü kullanıldığının bir göstergesi olduğunu, Çomaklı ve ark. (2012) ise çoğalıcı ve istilacı bitkiler kötü kullanılan meralarda iyi kalitedeki türlerin yerini aldığını ifade etmektedir. Ayrıca Şengönül ve ark. (2009), azalıcılar hayvanların severek otladığı bol üretim gücüne sahip türlerdir. Çoğalıcılar hayvanların otlamada isteksiz davrandığ İstilacılar ise hayvanların otlamadı $\breve{g}_{1}$ lezzetsiz, dikenli veya zehirli türlerden meydana gelmektedir. Mera hayvanları öncelikle alandaki lezzetli (azalıcı bitkiler) türleri, daha sonra çoğalıcı (az lezzetli)

Tablo 6. Çayırlı köyü merasının iki farklı yükseltisinde saptanan türler, türlerin familyaları, ömür uzunlukları, otlatmaya karşı tepkileri (Etki), toprağı kaplama oranları (TKO) ve botanik kompozisyondaki oranları (BKO)

\begin{tabular}{|c|c|c|c|c|c|c|}
\hline Türler & Familyası & Ömrü & Grubu & Etki & TKO & $\mathrm{BKO}$ \\
\hline \multicolumn{7}{|c|}{$863 \mathrm{~m}$} \\
\hline Carduus pycnocephalus & Asteraceae & Tek yıllık & İstilac1 & 10 & 2.50 & 3.97 \\
\hline Copsella bursa-pastoris & Brasscaceae & Tek yıllık & İstilacı & 15 & 3.75 & 5.95 \\
\hline Crepis sancta & Asteraceae & Tek yıllık & İstilacı & 2 & 0.50 & 0.79 \\
\hline Erodium cicutarium & Geraniaceae & Tek yıllık & İstilacı & 5 & 1.25 & 1.98 \\
\hline Eryngium campestre & Apiaceae & Çok yıllık & İstilacı & 6 & 1.50 & 2.38 \\
\hline Geranium molle & Geraniaceae & Tek yıllık & İstilac1 & 12 & 3.00 & 4.76 \\
\hline Helianthemum ledifolium & Cistaceae & Tek yıllık & İstilacı & 15 & 3.75 & 5.95 \\
\hline Lamium amplexicaule & Lamiaceae & Tek yıllık & İstilac1 & 18 & 4.50 & 7.14 \\
\hline Parentucellia latifolia & Scrophulariaceae & Tek yıllık & İstilac1 & 10 & 2.50 & 3.97 \\
\hline Notobasis syriaca & Asteraceae & Tek yıllık & İstilacı & 12 & 3.00 & 4.76 \\
\hline Aegilops umbellulata & Poaceae & Tek yıllık & İstilac1 & 15 & 3.75 & 5.95 \\
\hline Avena sterilis & Poaceae & Tek yıllık & İstilacı & 12 & 3.00 & 4.76 \\
\hline Bromus tectorum & Poaceae & Tek yıllık & İstilac1 & 18 & 4.50 & 7.14 \\
\hline Bromus hordeaceus & Poaceae & Tek yıllık & İstilac1 & 11 & 2.75 & 4.37 \\
\hline Echinaria capitata & Poaceae & Tek yıllık & İstilacı & 13 & 3.25 & 5.16 \\
\hline Hordeum murinum & Poaceae & Tek yıllık & İstilac1 & 9 & 2.25 & 3.57 \\
\hline Onobrychis caput-galli & Fabaceae & Tek yıllık & İstilacı & 8 & 2.00 & 3.17 \\
\hline Astragalus hamosus & Fabaceae & Tek yıllık & İstilac1 & 10 & 2.50 & 3.97 \\
\hline Hymenocarpus circinnatus & Fabaceae & Tek yıllık & İstilac1 & 23 & 5.75 & 9.13 \\
\hline Medicago rigidula & Fabaceae & Tek yıllık & İstilac1 & 28 & 7.00 & 11.11 \\
\hline \multicolumn{7}{|c|}{$1083 \mathrm{~m}$} \\
\hline Phlomis bruguieri & Lamiaceae & Çok yıllık & İstilacı & 12 & 3.00 & 5.08 \\
\hline Carduus pycnocephalus & Asteraceae & Tek yıllık & İstilac1 & 15 & 3.75 & 6.36 \\
\hline Ranunculus arvensis & Ranunculaceae & Tek yıllık & İstilac1 & 20 & 5.00 & 8.47 \\
\hline Salvia multicaulis & Lamiaceae & Çok yıllık & İstilac1 & 18 & 4.50 & 7.63 \\
\hline Senecio vernalis & Asteraceae & Tek yıllık & İstilacı & 17 & 4.25 & 7.20 \\
\hline Sinapis arvensis & Brassicaceae & Tek yıllık & İstilacı & 25 & 6.25 & 10.59 \\
\hline Teucrium polium & Lamiaceae & Çok yıllık & Çoğalıcı & 10 & 2.50 & 4.24 \\
\hline Poa bulbosa & Poaceae & Çok yıllık & Çoğalıcı & 25 & 6.25 & 10.59 \\
\hline Aegilops umbellulata & Poaceae & Tek yıllık & İstilacı & 11 & 2.75 & 4.66 \\
\hline Bromus hordeaceus & Poaceae & Tek yıllık & İstilacı & 14 & 3.50 & 5.93 \\
\hline Avena sterilis & Poaceae & Tek yıllık & İstilacı & 2 & 0.50 & 0.85 \\
\hline Bromus tectorum & Poaceae & Tek yıllık & İstilacı & 8 & 2.00 & 3.39 \\
\hline Trifolium campestre & Fabaceae & Tek yıllık & İstilacı & 25 & 6.25 & 10.59 \\
\hline Trifolium stellatum & Fabaceae & Tek y1llık & İstilacı & 10 & 2.50 & 4.24 \\
\hline Vicia sativa & Fabaceae & Tek yıllık & İstilacı & 8 & 2.00 & 3.39 \\
\hline Trifolium nigrescens & Fabaceae & Tek yıllık & İstilacı & 5 & 1.25 & 2.12 \\
\hline Astragalus hamosus & Fabaceae & Tek yıllık & İstilac1 & 11 & 2.75 & 4.66 \\
\hline
\end{tabular}


bitkileri tercih etmektedirler. Bunun sonucunda alandaki lezzetli ve tercih edilen bitkiler aşırı derecede azalmakta buna karşılık çoğalıcı ve istilacı türler alanı kapladığını vurgulamaktadır. Bazı araştırıcılar (Gökkuş, 1994; Altın ve ark., 2011; Çomaklı ve ark., 2012) ise, meralarda erken ve ağır otlatmanın sonucunda öncelikle azalıcı bitkiler ortamı terk ederler. Bunların yerine ortama öncelikle çoğalıcı türler katılır, kötü kullanım devam ederse çoğalıcı türlerde ortamdan uzaklaşarak yerlerini istilacı türlere terk ettiklerini belirtmektedir.

Bitki taksonları ile ilgili yapılan diğer bazı çalışmalarda araştırıcılar; Babalık ve Fakir (2017) Isparta meralarında 30 adet; Dursun ve Babalık (2018) Isparta meralarında 33 adet; Babalık ve Ercan (2018) Eskişehir meralarında 49 adet farklı familya tespit ettiklerini vurgulamaktadırlar. Ayrıca; Seydoşoğlu ve Kökten (2018) Batman meralarında 117 tür tespit ettiklerini ve türlerin 17 tanesi buğdaygil, 32 tanesi baklagil, 68 tanesi ise diğer familya bitkilerinden oluştuğunu ifade etmektedirler. Diyarbakır meralarında yapılan benzer bir çalışmada (Seydoşoğlu, 2018) 11 familyaya ait 36 taksonun tespit edildiği, bunlardan 13 tanesi Fabaceae, 7 tanesi Gramineae ve geri kalanı ise diğer familyalara ait olduğu ifade edilmektedir. Palta ve Genç Lermi (2018) Bartın ilinde yürütülen bir çalışma ile elde edilen 54 bitki taksonun 12 tanesi azalıcılar, 10 tanesi çoğalıcılar ve 32 tanesi ise istilacılar grubunda; Seydoşoğlu ve Kökten (2018) Batman ili Beşiri ilçesinde 117 tür tespit edilmiştir. Tespit edilen türlerden 7 adet azalıcı, 8 adet çoğalıcı ve 102 adet istilacı; Seydoşoğlu ve ark. (2018) tarafından Mardin ilinin meralarında yürütülen çalışmada toplam 132 bitki türüne ulaşılmıştır. $\mathrm{Bu}$ bitki türlerinin 5 tanesi azalıcı, 5 tanesi çoğalıcı ve 122 tanesi de istilacı olduğunu bildirmişlerdir.

İncelenen merada elde edilen bulgular, literatür bulgularıyla karşılaştırıldığında; genel olarak farklılıkların olduğu ve istilacı türlerin çoğunlukta olduğu görülmektedir. $\mathrm{Bu}$ farklılıklar; mera amenajman ilkelerine uyulmadan yapılan aşırı otlatma, mera alanının topoğrafik yapısı, vejetasyon ölçme yöntemi ve ekolojik faktörlerden kaynaklandığı söylenebilir.

\subsection{Mera durumu ve mera sağlığı}

Vejetasyon etütleri ile incelenen her iki yükseklikteki meraların Tablo 3'e göre "zayıf mera" ve "riskli mera" sinıfına girdiği belirlenmiştir.

Vejetasyonda bulunan iyi cins yem bitkileri miktarı esas alınarak yapılan sınıflandırmaya göre; İncelenen mera yukarıdaki sınıflandırmaya göre değerlendirildiğinde; otlatma yoğunluğu, uygun hayvan tipi ile otlatılmama, otlatma mevsimine uyulmaması gibi yanlış kullanım sonucu hızlı bir yıpranma ve iklim faktörlerinden kaynaklı çok zayıf mera sınıfinda olduğu söylenebilir. Zayıf mera sınıfında değerlendirilen çalışma konusu merada otlatma baskısı daha fazla olduğu için mera vejetasyonunda önemli farklılıklar meydana gelmiştir. $\mathrm{Bu}$ durum meranın botanik kompozisyonunda azalıcı türlerin tükenmesine, istilacı türlerin ise hızlı bir artış eğilimi göstererek tüm alanı kaplamasına neden olmuştur.

\section{Sonuçlar}

İncelenen merada genel olarak istilacı türlerin baskın olduğu görülmüştür. Ülkemizin meralarında olduğu gibi araştırma alanı mera kesimleri üzerinde de aşırı, erken ve düzensiz otlatmanın olduğu ve bu nedenle mera amenajman yönetimi, otlatma mevsimine ve otlatma kapasitesine göre planlanmalıdır. İncelenen mera alanları riskli ve zayıf mera sinıfında yer aldığından dolayı otlatılmaya kapatılmalı ve 1slah metot çalışmalarıyla üstten tohumlama, gübreleme ve yabancı otlarla mücadele edilmelidir. Böylece, mera yönetimi ve 1slah yöntemleriyle doğal dengeyi bozacak uygulamaların önüne geçilmesi planlanmalı ve elde edilen sonuçların benzer çalışmalara 1şık tutması amaçlanmalıdır.

\section{Kaynaklar}

Açıkgöz, E., 1995. Yem Bitkileri (2. Bask1). Uludağ Üniversitesi Ziraat Fakültesi Yayınları, No: 7-0250210, Bursa.

Adams, B.W., Willms, W.D., Smoliak, S., Wroe, R.A., 1986. Range It's Nature and Use. Alberta Forestry, Land and Wildlife, Public Lands Division, Publication No: I/11, Alberta.

Alay, F., İspirli, K., Uzun, F., Çınar, S., Aydın, İ., Çankaya, N., 2016. Uzun süreli serbest otlatmanın doğal meralar üzerine etkileri. Gaziosmanpaşa Üniversitesi Ziraat Fakültesi Dergisi, 33(1): 116124.

Altın, M., Gökkuş, A., Koç, A., 2011. Çayır Mera Yönetimi. I. Cilt (Genel İlkeler), T.C. Tarım ve Köyişleri Bakanlığı, Tarımsal Üretim ve Geliştirme Genel Müdürlüğü, Ankara.

Anonim, 2017. Kurtalan İlçesi İklim Verileri. T.C. Tarım ve Orman Bakanlığı, Meteoroloji 15. Bölge Müdürlüğü, Diyarbakır.

Anonim, 2008. Türkiye'nin Çayır ve Mera Bitkileri. T.C. Tarım ve Köyişleri Bakanlığı, Ankara.

Ayan, İ., Mut, H., Acar, Z., Başaran, U., Töngel, M.Ö., Aşçı, Ö.Ö., 2007. Samsun ili kıyı kesiminde yer alan taban meraların bitki örtüsü, toprak özellikleri ve bazı sorunlar. Türkiye VII. Tarla Bitkileri Kongresi, 25-27 Haziran, Erzurum, s. 54-57. 
Aydın, İ., Uzun, F., 2000. Lâdik ilçesi Salur köyü merasında farklı 1slah metotlarının of verimi ve botanik kompozisyon üzerine etkileri. Turkish Journal of Agricultural and Forestry, 24(2): 301-307.

Babalık, A.A., Fakir, H., 2017. Korunan ve otlatılan mera alanlarında vejetasyon özelliklerinin karş1laştırılması: Kocapınar merası örneği. Türkiye Ormancllik Dergisi, 18(3): 207-211.

Babalık, A.A., Ercan, A., 2018. Eskişehir ili Karaören köyü merasının vejetasyon özelliklerinin belirlenmesi. Turkish Journal of Forestry, 19(3): 246251.

Bakoğlu, A., Koç, A., 2002. Otlatılan ve korunan iki farklı mera kesiminin bazı toprak ve bitki örtüsü özelliklerinin karşılaştırılması, bitki örtüsü özelliklerinin karşılaştırılması. Firat Üniversitesi Fen ve Mühendislik Bilimleri Dergisi, 14(1): 37-47.

Çınar, S., Hatipoğlu, R., Avcı, M., İnal, İ., Yücel, C., 2018. Adana ili Tufanbeyli ilçesi meralarının botanik kompozisyonunun belirlenmesi üzerine bir araştırma. Türk Doğa ve Fen Dergisi, 7(2): 21-29.

Çomakl1, B., Öner, T., Daşcı, M., 2012. Farklı kullanım geçmişine sahip mera alanlarında bitki örtüsünün değişimi. Iğdır Üniversitesi Fen Bilimleri Enstitüsü Dergisi, 2(2): 75-82.

Davis, P.H., 1969. Flora of Turkey and the Eastaege an Islands. University of Edinburg Press, Volume 1-3, Edinburgh.

Demiri, M., 1983. Flora Ekskursioniste e Shqiperise. Shtepia Botuese e Librit Shkollor, Tirana.

Dursun, İ., Babalık, A.A., 2018. Isparta ili Çatoluk ormaniçi merasının vejetasyon yapısının belirlenmesi. Turkish Journal of Forestry, 19(3): 233239.

Edgecombe, W., 1964. Weeds of Lelanon. Faculty of Agriculture SciencesAmerican University of Beirut, Publication No: 24, Lebanon.

Fitter, A.H., 1994. Acquisition and utilization of resources. In M.J. Crawley (Ed.), Plant ecology. Blackwell Scientific Publications Inc., p. 375-405.

Garms, H., Eigener, W., Melderis, A., Pope, T., Durrell, G., 1968. The Natural History of Europe. Paol Hamilyn Limited, London.

Gökkuş, A., 1991. Doğu ve Güney Doğu Anadolu Bölgeleri Cayır Mera ve Yem Bitkileri ve Hayvancılığ 1 Geliştirme Projesi Eğitim Semineri, 2022 Şubat, Erzurum.

Gökkuş, A., 1994. Sürülüp Terkedilen Alanlarda Sekonder Süksesyon. Atatürk Üniversitesi, No: 787, Ziraat Fakültesi No: 321, Araştırma No: 197, Erzurum.

Gökkuş, A., Koç, A., Çomaklı, B., 2000. Çayır-Mera Uygulama Kılavuzu. Atatürk Üniversitesi Ziraat Fakültesi Yayınları No: 142, Erzurum.

Holechek, J.L., Preper, R.D., Herbel, C.H., 2004. Range Management Principles and Practices. Pearson Education, Inc., New Jersey.

Huxley, A., Taylor, W., 1977. Flowers of Greece and the Aeg Eanchatto and Windusltd. Printed Great Britain by Richard Clay Ltd Bunges, Suffolk.
Koç, A., 1995. Topografya ile toprak nem ve sıcaklığının mer'a bitki örtülerinin bazı özelliklerine etkileri. Doktora tezi, Atatürk Üniversitesi, Fen Bilimleri Enstitüsü, Erzurum.

Koç, A., Çakal, Ş., 2004. Comparison of somerange landcanopy coverage methods. International Soil Congress Natural Resource Management for Sustainable Development, 7-10 June, Erzurum, s. 4145 ,

Koç, A., Gökkuş, A., Altın, M., 2003. Mera durumu tespitinde dünyada yaygın olarak kullanılan yöntemlerin mukayesesi ve Türkiye için bir öneri. Türkiye 5. Tarla Bitkileri Kongresi, 13-17 Ekim, Diyarbakır, s. 36-42.

Laycock, W.A., 1989. Secondary succession and range condition criteria: Introduction to the problem. In W.K. Lauenroth and W.A. Laycock (Eds.), Secondary succession and the evaluation of rangeland condition, Westview Press Inc., pp. 1-15.

Öztan, Y., Okatan, A., 1985. Çayır Mera Baklagil ve Buğdaygil Yem Bitkilerinin Tanıtım Kilavuzu. Cilt II, Karadeniz Teknik Üniversitesi Orman Fakültesi, Karadeniz Üniversitesi Basımevi Genel Yayın No: 95, Fakülte Yayın No: 8, Trabzon.

Palta, Ş., Genç Lermi, A., 2018. Bartın ili Kutlubey Demirci köyü merasının bazı özelliklerinin belirlenmesi. Bartın Orman Fakültesi Dergisi, 20(2): 352-359.

Polunin, O., Huxley, A., 1974. Flowers of the Mediterranean Chatto and Windus, London.

Şengönül, K., Kara, Ö., Palta, Ş., Şensoy, H., 2009. Bartın Uluyayla yöresindeki mera vejetasyonunun bazı kantitatif özelliklerinin saptanması ve ekolojik yapının belirlenmesi. Bartın Orman Fakültesi Dergisi, 11(16): 81-94.

Seydoşoğlu, S., 2018. Bazı doğal mera alanlarının bitki örtüsü özellikleri, mera durumu ve sağlığının belirlenmesi. Turkish Journal of Forestry, 19(4): 368373.

Seydoşoğlu, S., Çaçan, E., Sevilmiş, U., 2019. Determination of botanical composition, yield and pasture quality ratings of infertile pastures in Kozluk district of Batman province of Turkey. Fresenius Environmental Bulletin, 28(4A): 3388-3394.

Seydoşoğlu, S., Kökten, K., 2018. Batman ili Beşiri ilçesi mera vejetasyonlarının bazı özellikleri. Ege Üniversitesi Ziraat Fakültesi Dergisi, 55(4): 491497.

Seydoşoğlu, S., Kökten, K., 2019. Batman mera vejetasyonlarının bazı özellikleri. Harran Tarım ve Gida Bilimleri Dergisi, 23(1): 60-68.

Seydoşoğlu, S., Kökten, K., Sevilmiş, U., 2018. Mardin il ve ilçelerine Bağlı köy meralarının temel vejetasyon özellikleri. Türk Tarım ve Doğa Bilimleri Dergisi, 5(4): 406-413.

Töngel, M.Ö., Ayan, İ., 2005. Samsun ili çayır ve meralarında yetişen bazı zararlı bitkiler ve hayvanlar üzerindeki etkileri. Ondokuz Mayıs Üniversitesi Ziraat Fakültesi Dergisi, 20(1): 84-93. 
Tuna, C., 2000. Trakya yöresi doğal mera vejetasyonlarının yapısı ve bazı çevre faktörleri ile ilişkisi. Doktora tezi, Trakya Üniversitesi, Fen Bilimleri Enstitüsü, Edirne.

Turan, N., Özyazıc1, M.A., Tantekin, G.Y., 2015. Siirt ilinde çayır mera alanlarından ve yem bitkilerinden elde edilen kaba yem üretim potansiyeli. Türkiye Tarımsal Araştırmalar Dergisi, 2(1): 69-75.

Uzun, F., Garipoğlu, A.V., Algan, D., 2010. Meralarımızda görülen sarı peygamber çiçeği (Centaurea solstitialis L.)'nin bitkisel özellikleri ve kontrolü. Anadolu Tarım Bilimleri Dergisi, 25(3): 213-222.

Uzun, F., Alay, F., İspirli, K., 2016. Bartın ili meralarının bazı özellikleri. Türkiye Tarımsal Araştırmalar Dergisi, 3(2): 174-183.
Ünal, S., Karabudak, E., Öcal, M.B., Koç, A., 2011. Interpretations of vegetation changes of some villages rangelands in Çankırı province of Turkey. Turkish Journal of Field Crops, 16(1): 39-47.

Weymer, H., 1981. Lernt Pflanze Kennen Ferdinand Enke Verflog, Stuttgart.

Yavuz, T., Sürmen, M., Töngel, M.Ö., Avağ, A., Özaydın, K., Yıldız, H., 2012. Amasya mera vejetasyonlarının bazı özellikleri. Tarım Bilimleri Araştırma Dergisi, 5(1): 181-185.

Yıldız, A., Özyazıc1, M.A., 2017. Karasal iklim kuşağında bulunan bir meranın farklı yöneylerinde botanik kompozisyonun, ot verimi ve ot kalitesinin belirlenmesi. Türkiye Tarımsal Araştırmalar Dergisi, 4(3): 218-231. 